\title{
Modeling and Performance Analysis of Manufacturing Systems in Footwear Industry
}

\author{
Temesgen Garoma Abeya ${ }^{1^{*}}$ and Nahom Mulugeta ${ }^{2}$ \\ ${ }^{1}$ Mechanical Engineering Department, College of Engineering and Technology, Wollega University, \\ Post Box No: 395, Nekemte, Ethiopia \\ ${ }^{2}$ School of Mechanical and Industrial Engineering, Addis Ababa Institute of Technology (AAiT), Industrial \\ Engineering Chair, Post Box No: 1176, Addis Ababa University, Addis Ababa
}

\begin{tabular}{|c|c|}
\hline Abstract & Article Information \\
\hline $\begin{array}{l}\text { This study deals with modeling and performance analysis of footwear manufacturing using } \\
\text { arena simulation modeling software. It was investigated that modeling and simulation is a } \\
\text { potential tool for modeling and analysis of manufacturing assembly lines like footwear } \\
\text { manufacturing because it allows the researcher to experiment with different variables and } \\
\text { controls the manufacturing process without affecting the real production system. In this study } \\
\text { Arena simulation software is employed to model and measure performance of existing } \\
\text { manufacturing systems of footwear. A footwear assembly plant producing a moccasin model } \\
\text { shoe in Ethiopia with a total number of } 19 \text { major parts to be assembled on two consecutive } \\
\text { assembly lines (stitching and lasting) were selected for the model. Furthermore, } 39 \text { and } 37 \\
\text { activities were identified for stitching and lasting production line respectively. For each } \\
\text { activity, } 15 \text { numbers of observations have taken using stopwatch. All the collected data are } \\
\text { statistically analyzed using arena input analyzer for statistical significance and determination } \\
\text { of expressions to be used in simulation modeling. A standard validated simulation model was } \\
\text { developed and run for } 41 \text { replications. The result shows that the stitching assembly line is } \\
\text { operating with a line balance efficiency of } 58.7 \% \text { and lasting assembly line } 67.6 \% \text {. In the } \\
\text { course of action, about four major problems were identified and solved with five proposed } \\
\text { scenarios of which the best scenario results in improvement of assembly line balance } \\
\text { efficiency of } 93.5 \text { and } 86.3 \% \text { for stitching and lasting respectively. This Arena Simulation } \\
\text { Model has considered the production resources like machineries, employees and processing } \\
\text { time; activity precedence relationships; and production methods in developing and testing } \\
\text { scenarios. It can be applied to other complex manufacturing industries wishing to analyze and } \\
\text { improve the performance of the production systems. } \\
\text { Copyright@2014 STAR Journal All Rights Reserved }\end{array}$ & $\begin{array}{l}\text { Keywords: } \\
\text { Modeling } \\
\text { Simulation } \\
\text { Performance Analysis } \\
\text { Footwear Manufacturing } \\
{ }^{*} \text { Corresponding Author: } \\
\text { Temesgen Garoma } \\
\text { E-mail: } \\
\text { temgarom@yahoocom }\end{array}$ \\
\hline
\end{tabular}

\section{INTRODUCTION}

In today's competitive global market, companies are mostly striving to strengthen themselves as much as possible in all competiveness dimensions of business. These demands for optimal production systems which increases the overall performance of the companies. Survival of any business in today's competitive market place depends mainly on response time, production cost, market price and flexibility of manufacturing. These things motivated continuous research in modeling and performance evaluation of manufacturing systems. In parallel to this, different simulation software play a great role in designing a model of a real system and conducting experiments with this model for the purpose of understanding the behavior of the system and evaluating various strategies and scenarios for the operating or manufacturing systems

Leather industry is one of the world's major industries and the footwear industry is a substantial one within the supply chain of leather industry. Footwear is one of the goods which are manufactured on assembly line system. As shown in Figure 1, the production process of Shoe manufacturing is most likely labor intensive process and it cannot be fully automated. It requires craftsmanship in each phase of the production. More than a hundred operations are required for making a pair of shoes. With the development of the footwear machines, the production time has been reduced and processes are performed separately.

Depending on the type of shoes and material usage, the manufacturing process can vary. The footwear company has mainly five sections/departments in which a progressive route is followed in order to produce the final product. These are technical design and styling, cutting department, closing (stitching) department, lasting and making department, and finishing department as depicted in Figure 1. 


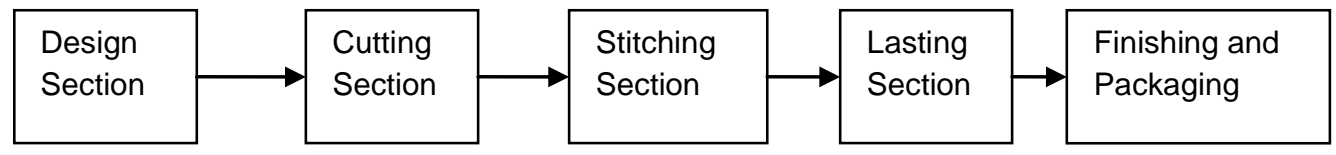

Figure 1: Production process of a shoe

This study presents simulation modeling and performance analysis using arena simulation software to solve the assembly line balancing problem (ALBP) with different scenarios to improve the efficiencies in footwear industry by concentrating on the stitching assembly line and lasting assembly line which are the major bottle neck section in footwear production. This study also focuses on Ethiopian Manufacturing Industry practice with a case study of which the name of the factory is not mentioned. It is organized as follows. Section 1 introduction; section 2 reviews related literature; section 3 defines the methods and materials; section 4 presents results, discussion, and proposed solutions, and section 5 draws conclusions and provides future work directions.

Even though we have moved beyond the Industrial Age and into the Information Age, manufacturing industry remains an important part of the global economy. There have been numerous efforts to use modeling and simulation tools and techniques to improve manufacturing efficiency over the last four decades. While much progress has been made and an increasing number of manufacturing system decisions is being made based on the use of models, their use is still sporadic in many manufacturing environments. It is believed that there is a need for pervasive use of modeling and simulation for decision support in current and future manufacturing systems (John W. Fowler and Oliver Rose, 2010).

According to Anu Maria (1997), modeling is the process of producing a model; a model is a representation of the construction and working of some system of interest. A model is similar to but simpler than the system it represents. One purpose of a model is to enable the analyst to predict the effect of changes to the system. On the one hand, a model should be a close approximation to the real system and incorporate most of its salient features. On the other hand, it should not be so complex that it is impossible to understand and experiment with it. A good model is a judicious tradeoff between realism and simplicity. Simulation practitioners recommend increasing the complexity of a model iteratively. An important issue in modeling is model validity. Model validation techniques include simulating the model under known input conditions and comparing model output with system output.

Chance, Robinson and Fowler (1996) clearly set that models are intended to support management decisions about the system and a single model will often not be capable of supporting all decisions. Rather, different decisions require different models because various aspects of the design and operation of the system will be important for the questions being asked of the model. While spreadsheet and queuing models are useful for answering basic questions about manufacturing systems, discrete event simulation models are often needed to answer detailed questions about how a complex manufacturing system will perform.

As Peer-Olaf Siebers (2006) examined, it is commonly observed that a gap exists between the performance predictions of a manufacturing system simulation model and the performance of the real system. As a consequence of abstraction and simplification, system models tend to model the real world too optimistically compared to real systems. Another common observation is that performance predictions of systems involving a high proportion of manual tasks are notably less accurate than those of highly automated systems (Figure 2).

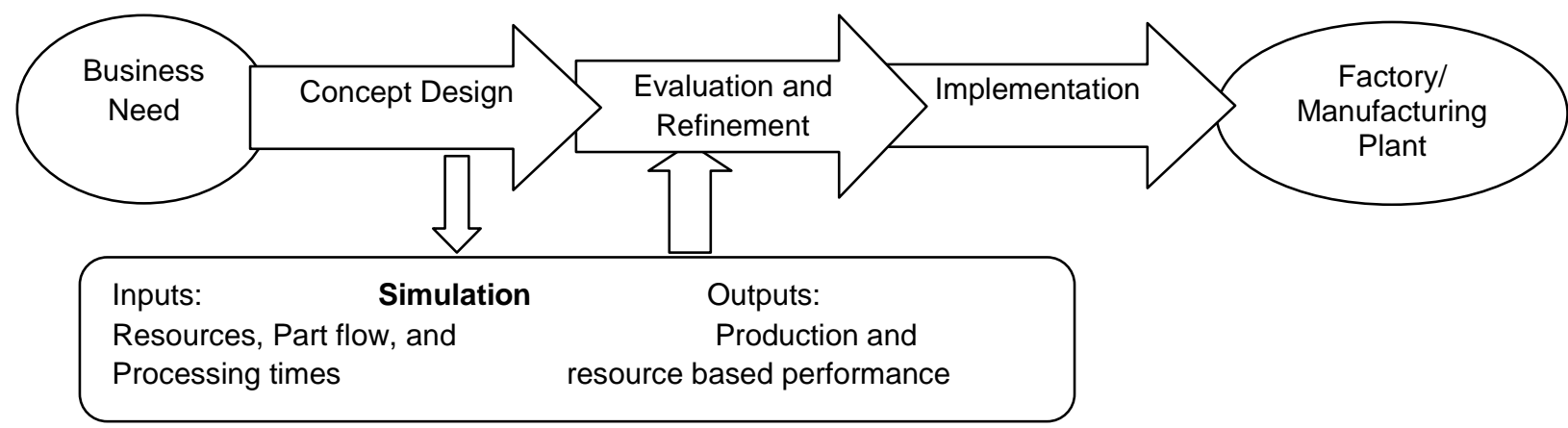

Figure 2: Steps in manufacturing systems design (Adopted from Peer-Olaf Siebers, 2006)

The term "Simulation" refers to a broad collection of methods and applications to mimic the behavior of real systems (Kelton et al., 2000). This is normally performed by developing a simulation model on a computer with appropriate software.

According to Yücesan and Fowler, (2000), simulation has several strengths including:

- Time compression - the potential to simulate years of real system operation in a much shorter time,
- Component integration - the ability to integrate complex system components to study their interactions,

- Risk avoidance - hypothetical or potentially dangerous systems can be studied without the financial or physical risks that may be involved in building and studying a real system,

- Physical scaling - the ability to study much larger or smaller versions of a system, 


\section{Temesgen Garoma and Nahom Mulugeta}

- Repeatability - the ability to study different systems in identical environments or the same system in different environments, and

- Control - everything in a simulated environment can be precisely monitored and exactly controlled.

\section{Line Balancing Problem}

One important aspects of manufacturing system is line balancing problem. Assembly line balancing (ALBP) is the problem of assigning various tasks to workstations, while optimizing one or more objectives without violating any restrictions imposed on the line. ALBP has been an active field of research over the past decades due to its relevancy to diversified industries such as garment, footwear and electronics (James C. Chen, Chun-Chieh Chen and Yi-Jhen Lin, 2014).

As Groover (2000) states the assembly line must be designed to achieve a production rate $(R)$ sufficient to satisfy demand for the product. This production rate must be converted to a cycle time $(\mathrm{T})$, which is the time interval at which the line will be operated. The cycle time must take into account the reality that some production time will be lost due to occasional equipment failures, power outages, lack of a certain component needed in assembly, quality problems, labor problems and other reasons. As a result of these losses, the line will be up and operating only a certain proportion of time out of the total shift time available; this uptime proportion is referred to as the line efficiency. Hence;

$\mathrm{Tc}=60 \mathrm{E} / \mathrm{Rp}$

Where Tc is cycle time of the line (min/cycle) and Rp is required production rate (units/hr) and $\mathrm{E}$ means line efficiency. Typical values of $E$ for a manual assembly line are in the range of 0.90-0.98 (Groover, 2000).

\section{Measures of Line Balance Efficiency}

Because of the difference in minimum rational work element times and the precedence constraints among the elements, it is virtually impossible to obtain a perfect line balance. Measures must be defined to indicate how good a given line balancing solution is. One possible measure is balance efficiency, which is the work content time divided by the total available service time on the line (Groover, 2000).

$$
\mathrm{E} b=\mathrm{T} \text { wc/wTs..... }
$$

Where Eb is balance efficiency, often expressed as a percentage; Ts is the maximum available service time on the line and $w$ is number of workers. The complement of balance efficiency is balance delay, which indicates the amount of time lost due to imperfect balancing as a ratio to the total time available.

$\mathrm{d}=(\mathrm{wT} \mathrm{s}-\mathrm{Twc}) / \mathrm{wTs}$.

Where $\mathrm{d}$ is balance delay; and the other terms have the same meaning as before. A balance delay of zero indicates a perfect balance. It could be easily deducted that the following formula is used for validation of results about Eb and d.

$E b+d=1$

\section{Arena Simulation Modeling}

Simulation is one of several alternative methods of analyzing systems. Another technique is the use of mathematical analysis. Analytical modeling involves building a system description using some formal,
Sci. Technol. Arts Res. J., July-Sep 2014, 3(3): 132-141

mathematical notation. Unfortunately mathematical analysis is limited to a relatively small number of simple systems and the opportunity to represent manufacturing systems in this way is felt to be limited (Chance, Robinson and Fowler, 1996).

In a simulation, the analyst controls all the factors making up the data and can manipulate them systematically to see directly how specific problems and assumptions affect the analysis. Because simulation software keeps track of statistics about model elements, performance can be evaluated by analyzing the model data.

The Arena modeling system from Systems Modeling Corporation is a flexible and powerful tool that allows analysts to create animated simulation models that accurately represent virtually any system. First released in 1993, Arena employs an object-oriented design for entirely graphical model development. Simulation analysts place graphical objects called modules on a layout in order to define system components such as machines, operators, and material handling devices (David, 1997 and Kelton, 2000).

Arena is built on the SIMAN simulation language. After creating a simulation model graphically, Arena automatically generates the underlying SIMAN model used to perform simulation runs (David, 1997 and Kelton, 2000). Arena allows the interactions with other computer tools such as Visual Basic, Excel, etc., and it is very well integrated in Windows environment. With Arena, it is possible to choose the level of complexity by using " basic features " or features that are more specific. It is even possible to create customized tools in the program (Desalegn Hailemariam, 2009).

Consequently, Arena is a very good tool for doing research, since it can be linked with other programs in Windows environment and models as complex and accurate as needed can be created. Because of the above advantages of the software and its availability (student version); Arena simulation software is selected for this research work. The commercial version software is available in the market but it is expensive to afford. Therefore, by taking some assumptions it is decided to use the student version Arena software.

Other important features of Arena Simulation modeling is determination of replication numbers. Since the individual replication results are independent and identically distributed, you could form a confidence interval for the true expected performance measures, which is assumed sample mean across an infinite number of replications. Hence, it is determined by using the following formula (Keliton, 2000).

$\mu=X \pm t_{n-1,1-\alpha / 2} S /$ squarerootn

Where $\mu$ is the assumed sample mean across an infinite number of replications, $X$ is the sample mean, $S$ is the sample standard deviation, $\mathrm{n}$ is the number of replications, and $t_{n-1,1-\alpha / 2}$ is the upper $1-\alpha / 2$ critical point from Student's t distribution with n-1 degree of freedom. In almost all arena simulation modeling a 95\% confidence interval $(\alpha=.05)$ is used.

In a simulation project, the ultimate use of input data is to drive the simulation model. This process involves the 


\section{Temesgen Garoma and Nahom Mulugeta}

collection of input data, analysis of the input data, and use of the analysis of the input data in the simulation model. Furthermore, Anu Maria(1997) has identified about 11 steps involved in developing a simulation model, designing a simulation experiment, and performing simulation analysis which are (1) Identify the problem, (2) Formulate the problem, (3) Collect and process real system data, (4) Formulate and develop a model, (5) Validate the model, (6)Document model for future use (7)Select appropriate experimental design, (8) Establish experimental conditions for runs, (9) Perform simulation runs, (10) Interpret and present results, and (11) Recommend further course of action. Although this is a logical ordering of steps in a simulation study, much iteration at various sub-stages may be required before the objectives of a simulation study are achieved. Not all the steps may be possible and/or required. On the other hand, additional steps may have to be performed. Therefore, the appropriate methodology has designed for this research as presented below.

\section{METHODS AND MATERIALS}

The standard methodology used for this research is a generally accepted computer simulation model. A footwear assembly plant producing a moccasin model shoe with a total number of 19 parts namely: Apron, Vamp, Apron lining, Vamp lining, Apron sponge, Vamp sponge, Counter ,Counter lining, Stiffener, Vamp reinforcement, Apron reinforcement, Insole, Sock lining, and Sock pad (sponge) to be assembled on two consecutive production process lines (stitch and finishing) were selected for the model. Activity identification in the production lines, process mapping to understand how the product(entities) are actually moving, processes time collection and analyzing using Built in Arena input analyzer, simulation model development and identification of replication numbers were the methodologies used .

\section{Data Collection and Analysis}

A Total number of 39 activities were identified for stitching assembly line and a total number of 37activities were identified for lasting assembly line as shown in table 1. Process maps for both types of production lines were developed based on an activity relationship and precedence rules as shown in Figure 4 and 5.

Since the model input is identified based on literature review and actual performance of the production lines the following variables which used in the measuring of the efficiency and effectiveness of the manufacturing process were collected. Therefore, data was collected regarding to total number of tasks, processing times of each task, transfer time of WIP between stations, priorities between processes, arrival frequencies of entities or time between arrival, manning level for each task, layout of machines distance $\mathrm{b} / \mathrm{n}$ machines (station), conveyor length and speed, working hours, production output, and defect rate (rework). For each activity, fifteen (15) numbers of observations have taken to increase the validities of input data. Table 1 shows lists of activity, number of workers and collected processing time expression to be used in the model.
Sci. Technol. Arts Res. J., July-Sep 2014, 3(3): 132-141

Identification of Best Statistical Distribution for Collected Data

At the third step the raw collected process time was analyzed using built in Arena Simulation Input Analyzer. One can see how an input data analyzer is analyzing and generate the results as shown in figure 3 for back lasting activity.

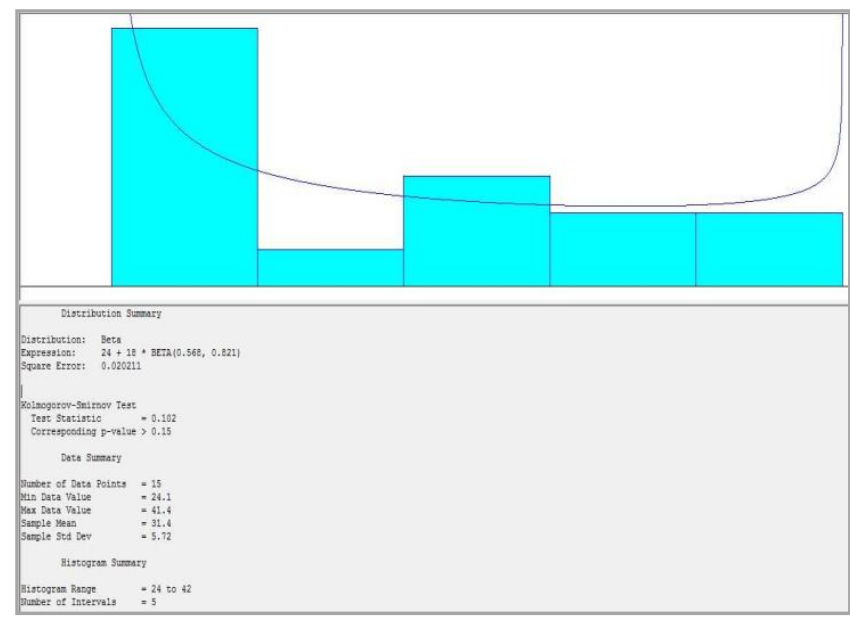

Figure 3: Input analyzer data distribution function window for Back Lasting Operation

As show in the figure the consents of the generated results contain the following information:

\section{Distribution Summary}

Distribution: Beta

Expression: $24+18$ * $\operatorname{BETA}(0.568,0.821)$

Square Error: 0.020211

Kolmogorov-Smirnov Test

Test Statistic $=0.102$

Corresponding $p$-value $>0.15$

\section{Data Summary}

Number of Data Points $=15$

Min Data Value $=24.1$

Max Data Value $=41.4$

Sample Mean $=31.4$

Sample Std Dev $=5.72$

\section{Histogram Summary}

Histogram Range $=24$ to 42

Number of Intervals $=5$

From the above data fit test, the function that best fits the distribution is the expression: $24+18$

$\operatorname{BETA}(0.568,0.821)$ and therefore back lasting operation follows the above distribution in the simulation process.

It was critical step to determine the best distribution because it affects the performance of the manufacturing system. In deciding which distribution to present, it tried to choose those that are simple to describe, implement and are reasonably efficient as well. The distributions that are occurring in continuous simulation are Uniform, Exponential, Erlang, Gamma, Weibull, Normal, Lognormal, Beta, Pearson Type V, Pearson Type VI, LogLogistic and Triangular (Kelton, 2000). In summary; input analyzer data distribution function for all processes of both assembly lines is shown in table 1. 
Table 1: Collected processing time expressions for each activity of assembly lines

\begin{tabular}{|c|c|c|c|c|c|c|c|}
\hline No & Operation Type & 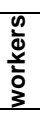 & Expression & No & Operation TYpe & 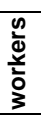 & Expression \\
\hline \multicolumn{4}{|c|}{ I. Stitching Assembly Line } & \multicolumn{4}{|c|}{ II. Lasting Assembly Live } \\
\hline 1 & Marking & 4 & $\begin{array}{l}126+41^{*} \mathrm{Beta} \\
(0583,0847)\end{array}$ & 2 & Sole peraiming & 1 & Triangular $(145,193,20)$ \\
\hline 2 & Skiving & 5 & Uniform $(186,225)$ & 3 & $\begin{array}{l}\text { Inserting upper in the last } \\
\text { (salentotechica } \mathrm{m} / \mathrm{c} \text { ) }\end{array}$ & 1 & $24+22$ * Beta $(0618,108)$ \\
\hline 3 & Printing size number & 1 & Normal $(153,165)$ & 4 & $\begin{array}{l}\text { Back centering (salento technical } \\
\mathrm{m} / \mathrm{c} \text { ) }\end{array}$ & 1 & 27+22 Expo (612) \\
\hline 4 & Sorting & 1 & $24+25^{\star}$ Beta $(0918,105)$ & 5 & Lasting margin gluing & 1 & $26+\log n(346,357)$ \\
\hline 5 & Apron gluing (upper) & 1 & $19+27^{\star}$ Beta $(0697,108)$ & 6 & Heating (RSF M/c04 & 1 & $29+28$ *Beta $(0476,176)$ \\
\hline 6 & Apron gluing (lining) & 1 & $20+$ Ereang $(46,2)$ & 7 & Side lasting (salento tecnica m/c & 1 & $31+24{ }^{*} \operatorname{Beta}(0822,0956)$ \\
\hline 7 & Vamp gluing (upper) & 1 & Triangular $(30,446,46)$ & 8 & Heating (RS FM/c04) & 1 & $23+$ Expo (483) \\
\hline 8 & Vamp gluing (lining) & 1 & Triangular $(31,35345)$ & 9 & Back lasting (RSF M/C 05) & 1 & $24+18$ *Beta $(0568,0821)$ \\
\hline 9 & $\begin{array}{l}\text { Sponge attaching to the } \\
\text { apron }\end{array}$ & 1 & $9+$ Long $(447,745)$ & 10 & Tack removing & 1 & $122+$ Erla $(0429,5)$ \\
\hline 10 & Sponge attaching the vamp & 1 & $\begin{array}{l}10+795 * \text { Beta }(162 \\
223)\end{array}$ & 11 & Heating (RSF M/C 06) & 1 & Constant (469) \\
\hline 11 & Apron pasting & 1 & Weib $(873,165)$ & 12 & Boiling (RSF M/C 19) & 1 & $35+$ weib $(125,161)$ \\
\hline 12 & Vamp pasting & 1 & Normal $(336,626)$ & 13 & Hammering & 1 & Triangular $(24,314,49)$ \\
\hline 13 & Vamp pressing & 1 & $18+11$ * Beta $(131,105)$ & 14 & Crime & 1 & $27+$ Erla $(199,3)$ \\
\hline 14 & Apron pressing & 1 & $31+19^{\star}$ Beta $(0671,147)$ & 15 & Ironing (RSF M/C 07) & 1 & - \\
\hline 15 & Recutting apron & 1 & Normal $(322,401)$ & 16 & Brushing & 1 & Triangular $(23,28,30)$ \\
\hline 16 & Recutting vamp & 1 & $9+$ Expo (396) & 17 & Sole marking & 1 & Triangular $(60,677,71)$ \\
\hline 17 & Vamp marking & 1 & $17+\operatorname{Gamm}(316,127)$ & 18 & Roughnening & 2 & $26+9$ *beta $(0676,117)$ \\
\hline 18 & Vamp skiving & 1 & $101+277^{*}$ Beta $(0772$ & 19 & Upper gluing $1^{\text {st }}$ & 1 & $8+7$ *beta $(105,1025)$ \\
\hline 19 & Back sime stitch & 1 & $\begin{array}{l}0766) \\
161+277 \text { * } \operatorname{Beta}(0772, \\
0766)\end{array}$ & $\begin{array}{l}20 \\
21\end{array}$ & $\begin{array}{l}\text { Sole gluing } \\
\text { Upper gluing } 2^{\text {nd }}\end{array}$ & $\begin{array}{l}1 \\
1\end{array}$ & $26+10 *$ beta $(138,148)$ \\
\hline 20 & Back sime taping & 1 & 13 +Erlag $(382,3)$ & 22 & Drying & - & Constant (48) \\
\hline 21 & Apron stitch & 1 & $23+\operatorname{Exp}(537)$ & 23 & Heat activations & 1 & Constant (24) \\
\hline 22 & Vamp stitch & 1 & $12+\operatorname{Gamma}(108,345)$ & 24 & Sole attaching & 1 & Triangular $(132,169,20)$ \\
\hline 23 & Counter gluing & 1 & $19+$ Gamma $(271,218)$ & 25 & Sole pressing & 1 & $26+$ Weib $(626,158)$ \\
\hline 24 & Stiffener gluing & 1 & $9+5{ }^{*}$ Beta $(0937,0692)$ & 26 & Sole edge clearing & 1 & Normal $(268,149)$ \\
\hline 25 & Pasting stiffener on counter & 1 & $10+\log n(47,467)$ & 27 & Frizzing & 1 & Content (23) \\
\hline 26 & Vamp gluing & 1 & $529+$ weib $(192,13)$ & 28 & Delasting & 1 & $13+$ Erla $(101,2)$ \\
\hline 27 & Pasting counter on vamp & 1 & Normal $(889,129)$ & 29 & Sock gluing & 1 & $13+\log n(289,24)$ \\
\hline 28 & $\begin{array}{l}\text { Hill grip (counter lining) } \\
\text { gluing) }\end{array}$ & 1 & $\begin{array}{l}35+61 * \text { Beta }(0431 \\
0458)\end{array}$ & 30 & Sock attaching & 1 & $16+$ Erla $(204,2)$ \\
\hline 29 & $\begin{array}{l}\text { Hill grip pasting on the } \\
\text { vamp }\end{array}$ & 1 & - & 31 & Cleaning and burning & 4 & Triangular $(40,625,115)$ \\
\hline 30 & $\begin{array}{l}\text { vamp } \\
\text { Counter stitffner }\end{array}$ & 4 & $35+61$ * Beta $(031$ & 32 & Edge coloring & 1 & $26+\log n(74,805)$ \\
\hline & & 4 & $0458)$ & 33 & Spray & 1 & Normal $(154,15)$ \\
\hline 31 & Hill grip trimming & 1 & $\begin{array}{l}11+553 \text { *Beta }(063, \\
0625)\end{array}$ & 34 & Brushing & 1 & Normal $(279,352)$ \\
\hline 32 & Binding taping & 2 & $19+10$ * Beta $(11,0761)$ & 35 & Tagging and inserting soft paper & 2 & $33+$ Erla $(558,2)$ \\
\hline 33 & Binding stitch & 4 & $72+$ weib $(247,104)$ & 36 & Final quality inspection & 2 & Uniform $(50,67)$ \\
\hline 34 & Binding hammering & 1 & $18+10 *$ Beta $(142,101)$ & 37 & Packing & 2 & $26+\operatorname{Gamm}(215,217)$ \\
\hline 35 & Binding stitch & 3 & $\begin{array}{l}36+42 \text { * Beta }(105 \\
0906)\end{array}$ & & Total & 38 & \\
\hline
\end{tabular}

36 Edge coloring of Apron $120+$ Erla $(165,2)$

37 Burning $211+15^{*}$ Beta $(119,169)$

38 Back Molding $117+\operatorname{Gamm}(179,13)$

39 Hand stitch $12 \quad 470+$ Expo (104)
65

\section{Development of Standard Simulation Model}

The important component of this research is developing Computer Simulation Model for purpose of experimentation. In this case the model development was started with the declaration of the entity, the location of the workstations, generating path network and resources, declaration of the arrival and processing programming Logic flow describes the way by which the entity acts during its journey in the simulation model. At the current student version arena simulation software, it is only possible to accommodate 150 entities in the simulation model. Hence, for the purpose of practical applications researchers has taken the following five assumptions in developing the simulation models:

- Two and more similar individual work elements which are done by a single worker are merged together

- An individual worker working on the machine is responsible for quality inspection on his/her work and previous work done in the upstream station. Therefore, 


\section{Temesgen Garoma and Nahom Mulugeta}

we add up $5 \mathrm{sec}$ of processing time for quality inspection on the basic processing time.

- The transportation time in between the adjacent stations is added up to the basic processing time of each station.

- The lasting assembly line is categorized as mixed model assembly line in which different models can be loaded at the same time. However; in model development of the assembly process on this line it is treated as multi model assembly line.

- Considering some unanticipated circumstances for example the machine may stack or fail for a while, the worker may take more time in repositioning the work
Sci. Technol. Arts Res. J., July-Sep 2014, 3(3): 132-141

piece, the worker may strolling around his/her station, the worker may be busy in doing some private task other than the intended one we add up $15 \%$ of the basic processing time as allowance to each basic processing time.

By considering the above assumptions all processing tasks, their predecessors, average processing time and manning level for each task listed in table 1 are modified for input model. Accordingly, the Computer Simulation Model for both types of production processes is shown in Figure 4 and 5 respectively.

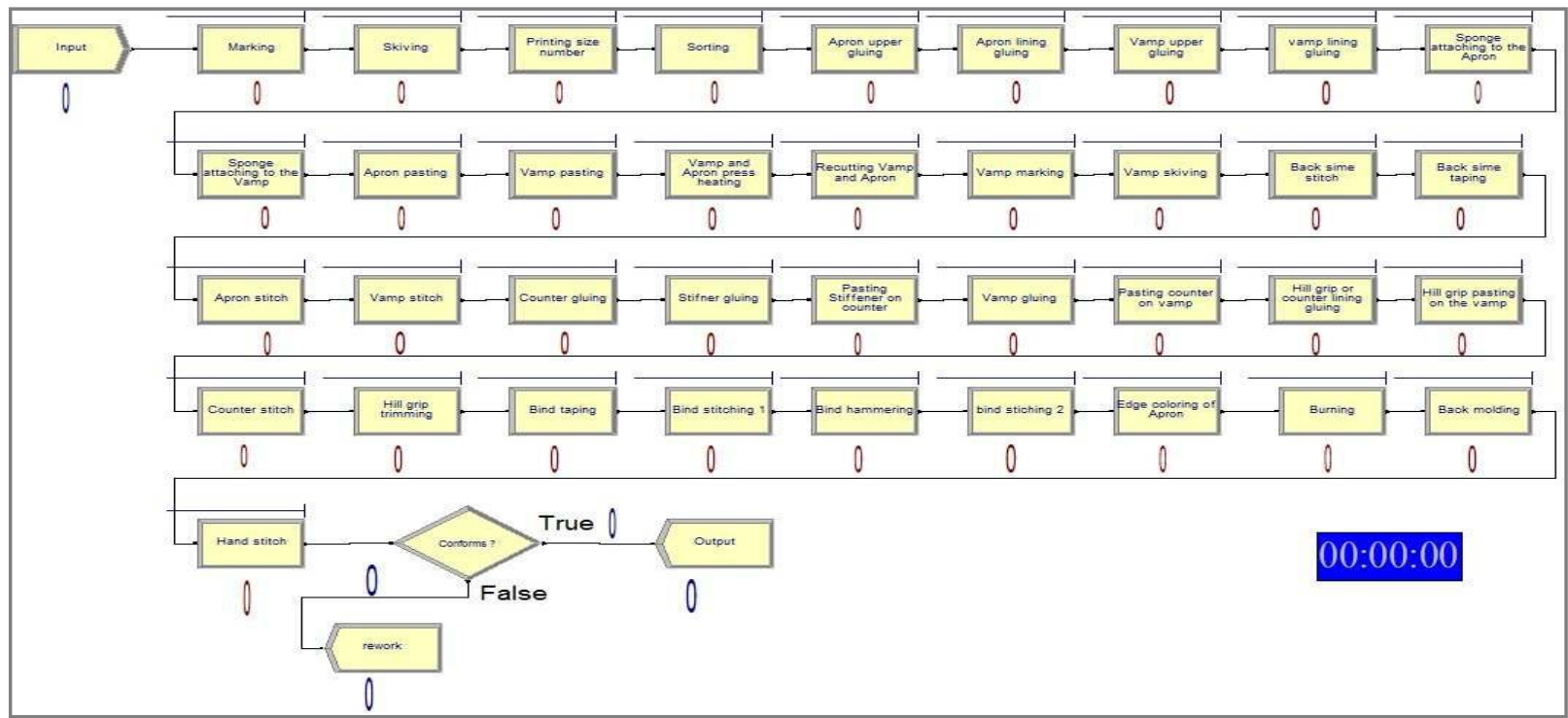

Figure 4: Stitching assembly line simulation model for existing manufacturing system

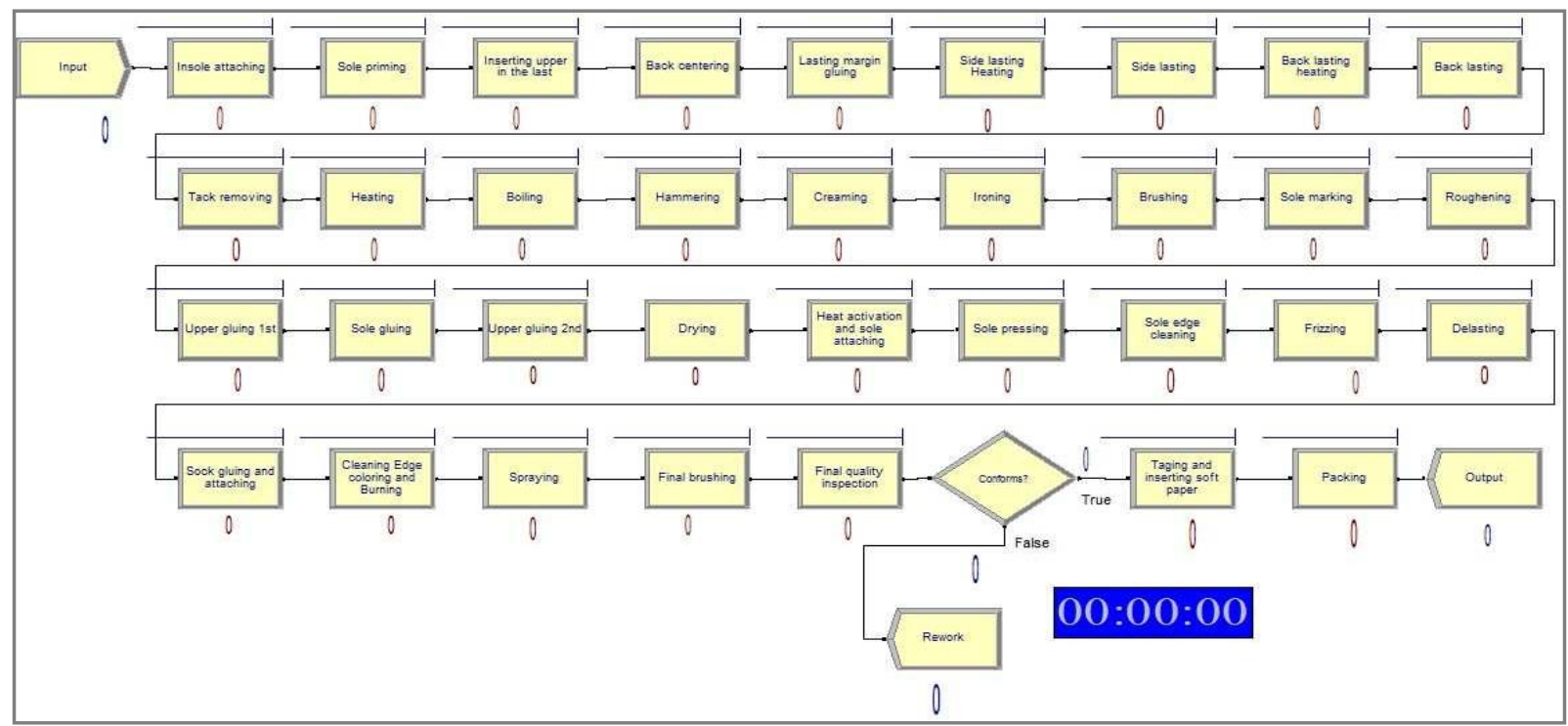

Figure 5: Lasting assembly line model for existing manufacturing system

\section{Calculations of Replication Number}

In order to determine the number of replications for the model, we have first calculated the mean and standard deviation of the first ten replication means as shown in table 2. The half width statistic is used to help in determining the reliability of the results from the replication. In other word half width is a sampling error we introduced in taking sample. Therefore, the value of half width can be determined by considering a 95\% confidence level where as the value of $t$ can be read from t probability distribution table.

Therefore, the percentage error for stitching assembly line equal to $(551.3+4.85) / 551.3=1.0088=0.88 \%$. Similarly the percentage error for lasting assembly line equal to $(522.4+1.79) / 522.4=1.0034=0.34 \%$.

Therefore, by using the replication calculation considered in the literature (equation 5), 41 replications 


\section{Temesgen Garoma and Nahom Mulugeta}

are required for both stitching assembly line and lasting assembly line which would give low acceptable error level.

Table 2: Mean, standard deviation and half width for initial 10 replication

\begin{tabular}{lccc}
\hline No & $\begin{array}{c}\text { Number of } \\
\text { Replications }\end{array}$ & $\begin{array}{c}\text { Stitching } \\
\text { Line Output }\end{array}$ & $\begin{array}{c}\text { Lasting } \\
\text { Line Output }\end{array}$ \\
\hline 1. & 1 & 555 & 523 \\
2. & 2 & 555 & 518 \\
3. & 3 & 558 & 524 \\
4. & 4 & 551 & 522 \\
5. & 5 & 562 & 526 \\
6. & 6 & 543 & 520 \\
7. & 7 & 542 & 522 \\
8. & 8 & 553 & 524 \\
9. & 9 & 551 & 520 \\
10. & 10 & 543 & 525 \\
\hline Mean & & $\mathbf{5 5 1 . 3}$ & $\mathbf{5 2 2 . 4}$ \\
Standard Deviation & $\mathbf{6 . 7 8}$ & $\mathbf{2 . 5}$ \\
Half width & & $\mathbf{4 . 8 5}$ & $\mathbf{1 . 7 9}$ \\
\hline \multicolumn{5}{l}{}
\end{tabular}

\section{Model Verification and Validation}

Model validation for this study is made using statistical validity by comparing the output of the real system and the simulation model output of the existing system. If there is no statistically significant difference between the data sets, then the model is considered valid. Conversely, if there is a statistically significant difference, then the model is not valid and needs additional work before further analysis may be conducted. The output of 7101 moccasin shoe model in the real manufacturing system at an average per eight hours; ranges from 210 to 412 shoes with an average output of 301 shoes.
Sci. Technol. Arts Res. J., July-Sep 2014, 3(3): 132-141

The output level of the simulation model offered per eight hour shift is 266 shoes at an average for lasting assembly line. Even the output of the real system highly varied, the output of the simulation model approaches the average output of the real system. Therefore, the model can be said to represent the real system, and is said to be valid. In addition to this; work stations with relatively high work in progress and low work in progress in real system are also observed in the simulation model.

In practical situations, in stitching assembly line hand stitching station is observed with high WIP in real system: in case of the running simulation model for this line, this station is registered with high level of WIP. Similarly other stations also observed the same phenomena. Therefore, this can also strongly validate the developed model to represent the real system.

\section{RESULTS}

The developed computer simulation model for footwear production system was run for performance analysis and the result is generated by Arena Output analyzer. This is done to predict the performance of a system or to compare the performance of two or more alternative system designs. Output analyzer also analysis and predicts the initial model performance and look after the weaknesses. The results of the model for both production lines are as show in table 3 . The capacity utilization of the existing manufacturing system at each stage are summarized and shown in figure 6 and 7 below.

Table 3: Performance measures by running the model (As-ls System)

\begin{tabular}{|c|c|c|c|}
\hline \multirow[b]{2}{*}{ No } & \multirow{2}{*}{ Performance Indicator } & \multicolumn{2}{|c|}{ Model Result } \\
\hline & & Stitching Assembly Line & Lasting Assembly Line \\
\hline 1 & Input & 657 & 554 \\
\hline 2 & Manning level & 65 & 36 \\
\hline 3 & Output $(P)$ per 8 hours & 561 shoes $=280.5$ pairs & 531 shoes \\
\hline 4 & Production rate $\left(R_{p}\right)=P / 480$ & 1.169 shoes / $\mathrm{min}$ & 1.106 shoes / $\mathrm{min}$ \\
\hline 5 & Make span or work content time $\left(\mathrm{T}_{\mathrm{wc}}\right)$ & $1825.01 \mathrm{sec}=30.4 \mathrm{~min}$ & $1127.72 \mathrm{sec}=18.8 \mathrm{~min}$ \\
\hline 6 & Work in process (WIP) & 68.1732 shoes & 22.73 shoes \\
\hline 7 & Production efficiency $\left(E_{p}\right)=$ Outpu & $561 / 657=0.854$ & $531 / 554=0.96$ \\
\hline 8 & Line Balance Efficiency $E_{b}$ & $1825.01 /\left(65^{\star} 47.85\right)^{\star} 100 \%=58.7 \%$ & $1127.72 /(36 * 46.31)^{*} 100 \%=67.6 \%$ \\
\hline
\end{tabular}

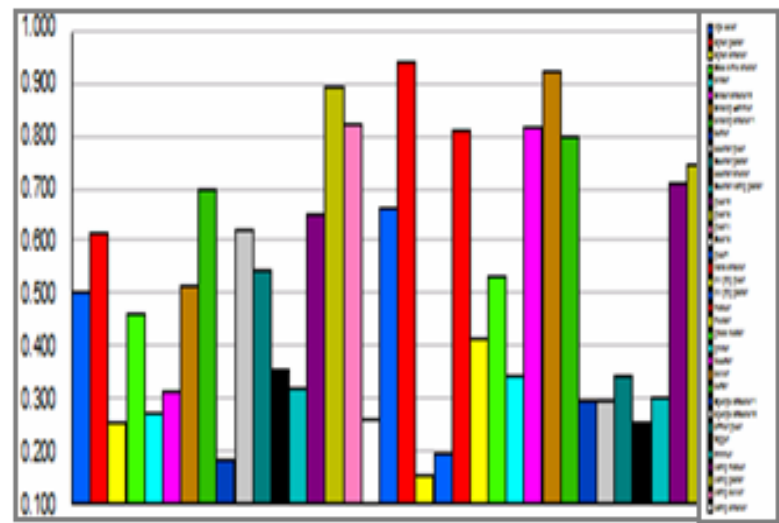

Figure 6: Capacity utilization of stitching assembly line resources

\section{DISCUSSION}

The output of the stitching line is the input for the lasting assembly line. However, in the real manufacturing system, it is observed that the output of the stitching assembly line is higher than the lasting assembly line. This phenomenon is also observed in the simulation model results in which the output of the stitching assembly

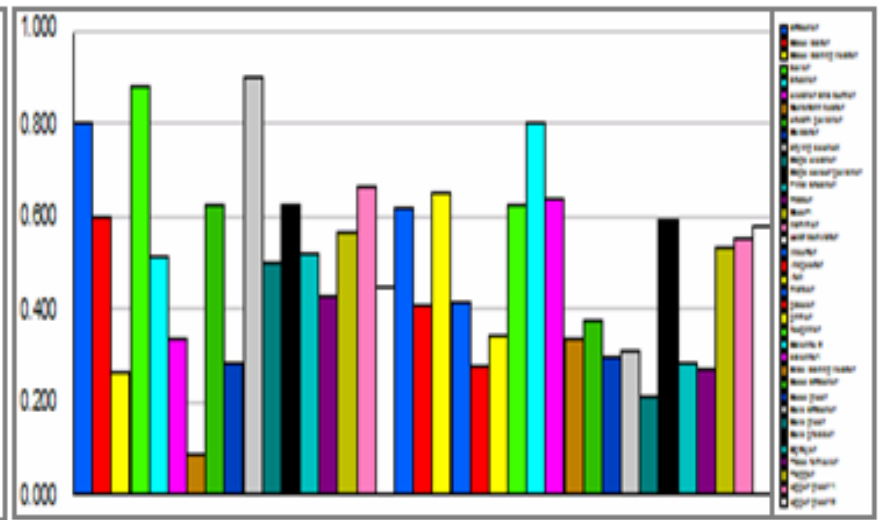

Figure 7: Capacity utilization of lasting assembly line resources

line is greater than the output of the lasting assembly line by 30 (561-531) on average. In other words, the output of the two assembly lines is not balanced. As a result of this, work in process (WIP) of different model shoes of every subsequent day are piled up in between these two lines. This piled up WIP in between the two lines makes difficult to schedule the overall production system. 


\section{Temesgen Garoma and Nahom Mulugeta}

In addition to this, it occupies large space, tide up capital and become sometimes difficult to match different models which create additional non value adding task. Moreover, Line balance efficiency for both assembly lines (58 \% and 67\%) respectively, is considerably below the typical values of good line balance efficiency of industrial manufacturing system which should be greater or equal to $80 \%$, conventional. Finally, relatively high level of WIP is observed in some work stations and low production output with respect to the installed capacity are the main problems observed during the study.

\section{Proposed Solutions}

In developing alternative solutions researchers have proposed and experimented with different Scenarios and come up with the following optimal solution:
Sci. Technol. Arts Res. J., July-Sep 2014, 3(3): 132-141

Scenario 1: Avoiding unnecessary duplication of resource from station with low capacity utilization.

Some stations have multiple resources but their capacity utilization is below $50 \%$. In these stations unnecessary duplication of resources exists. Therefore, these unnecessary duplication resources should be deducted from the line. From the capacity utilization graphs presented above these stations and their respective capacity and average number of busy resources are presented in table 4.

Scenario 2: Merging similar operations with low resource utilization together and assign to one worker.

Consecutive similar operations that can be merged together are listed in table 5, and these scenarios are modeled and simulated as shown in figure 8 and 9 .

Table 4: Stations with multiple resources of low capacity utilization (below 50\%)

\begin{tabular}{|c|c|c|c|c|c|}
\hline No & Station & $\begin{array}{c}\text { Resource } \\
\text { (man power) }\end{array}$ & $\begin{array}{c}\text { Scheduled } \\
\text { Capacity }\end{array}$ & $\begin{array}{c}\text { Average Number of } \\
\text { Busy Resources }\end{array}$ & $\begin{array}{c}\text { Deducted Resources } \\
\text { (Manpower) }\end{array}$ \\
\hline \multicolumn{6}{|c|}{ Stitching Assembly Line } \\
\hline 1 & Binding & Binder & 2 & 0.5415 & 1 \\
\hline 2 & Bind stitching & Bind stitcher 2 & 4 & 1.2635 & 2 \\
\hline 3 & Burner & Burner & 2 & 0.3701 & 1 \\
\hline \multirow[t]{2}{*}{4} & Counter stitching & Counter stitcher & 4 & 1.4119 & 2 \\
\hline & Total & & 12 & & 6 \\
\hline \multicolumn{6}{|c|}{ Lasting Assembly Line } \\
\hline 1 & Cleaning and burner & Cleaner and burner & 4 & 1.3495 & 2 \\
\hline & Total & & 4 & & 2 \\
\hline
\end{tabular}

Table 5: Similar and consecutive operations with low capacity utilization that can be merged together

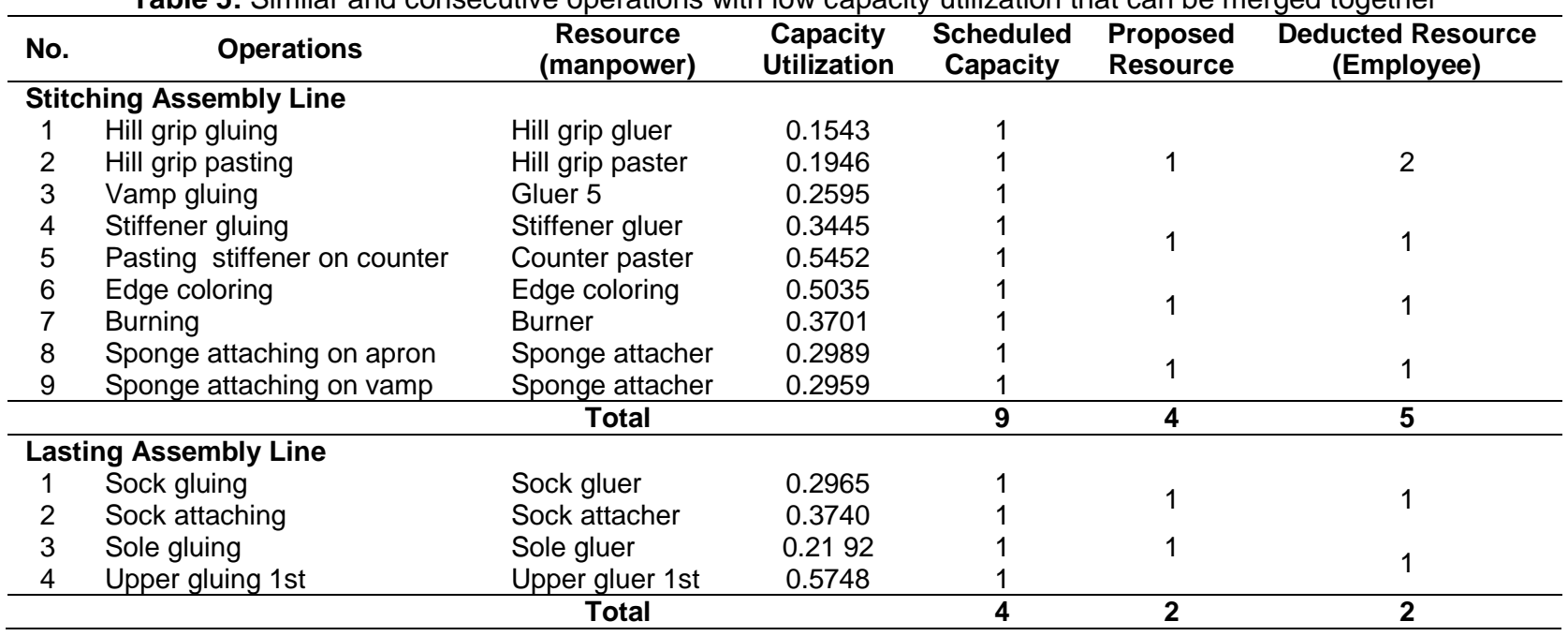

Running the simulation model of $1^{\text {st }}$ and $2^{\text {nd }}$ scenarios for stitching assembly line the production efficiency (Ep) is increased to $0.86(86 \%)$ and lasting assembly line becomes $95.7 \%$. furthermore, a total of 15 workers are reduced, without decreasing the output of both lines. Taking average direct labor salary equal to 780 Ethiopian Birr (ETB) at time of study 15 employee*780Birr *12 months result in 140,400 ETB savings annually.

Scenario 3: Increasing level of resource at stations with high work in process.

The level of WIP of each station of both lines is investigated. From the stitching assembly line hand stitch registered high level of WIP equal to 22.56, next is skiving station with relatively high level of WIP equal to 3.5800 then marking station follows. Therefore, adding resource to these stations would decrease the level of WIP from 68.17 to 52.94 and increase the output of the line from 561 to 593. By implementing this scenario the line balance efficiency $(\mathrm{E})$ becomes $63.5 \%$.

Furthermore, adding one more gluer to vamp upper gluing station and one more resource to Apron stitching station, the next station with maximum station service time; the maximum station service time goes to vamp lining gluing station with service time equal to $36.6 \mathrm{sec}$. manning level of the line is increased from 65 to 70 . Hence, line balance efficiency (Eb) will increases from 58.7 to $71.27 \%$. 


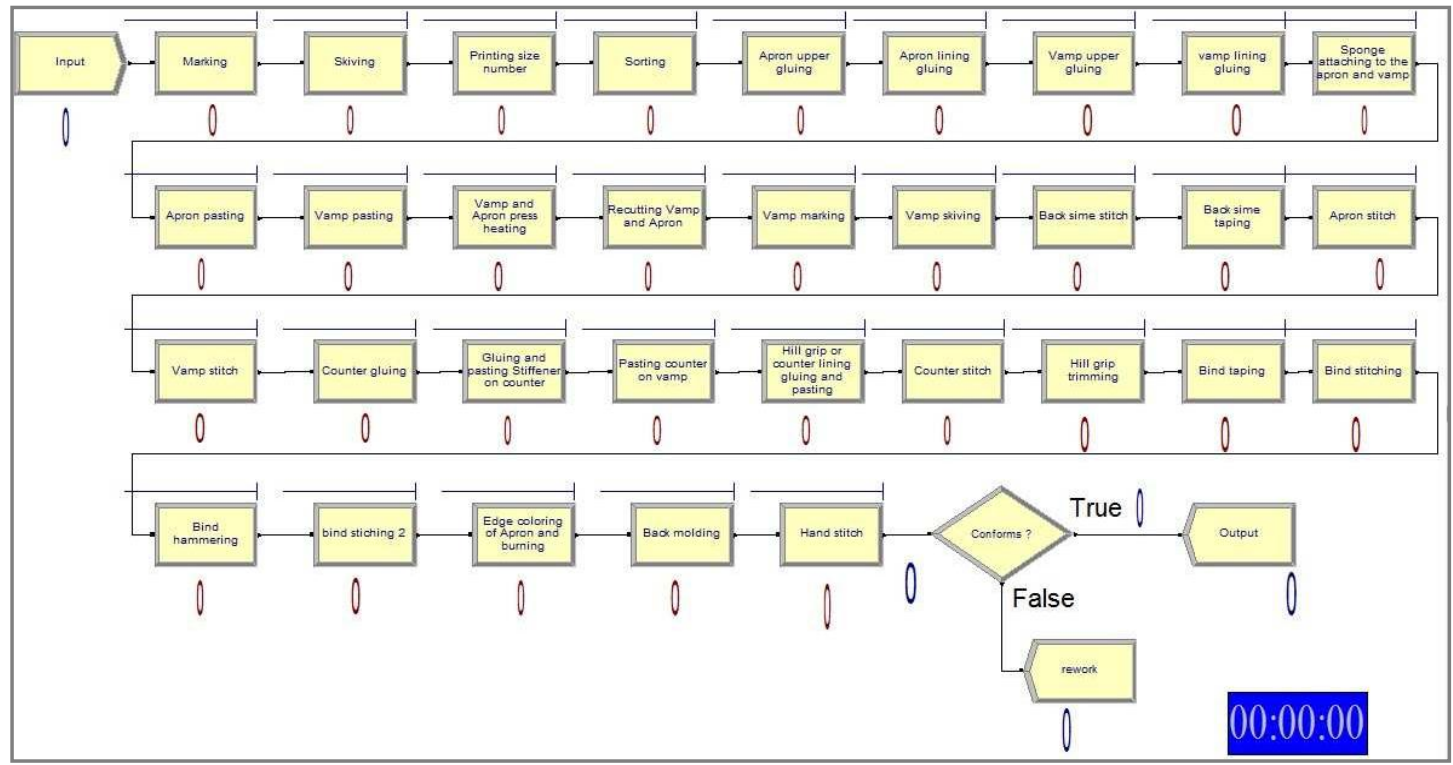

Figure 8: Proposed stitching assembly line simulation model for scenario 1 and 2

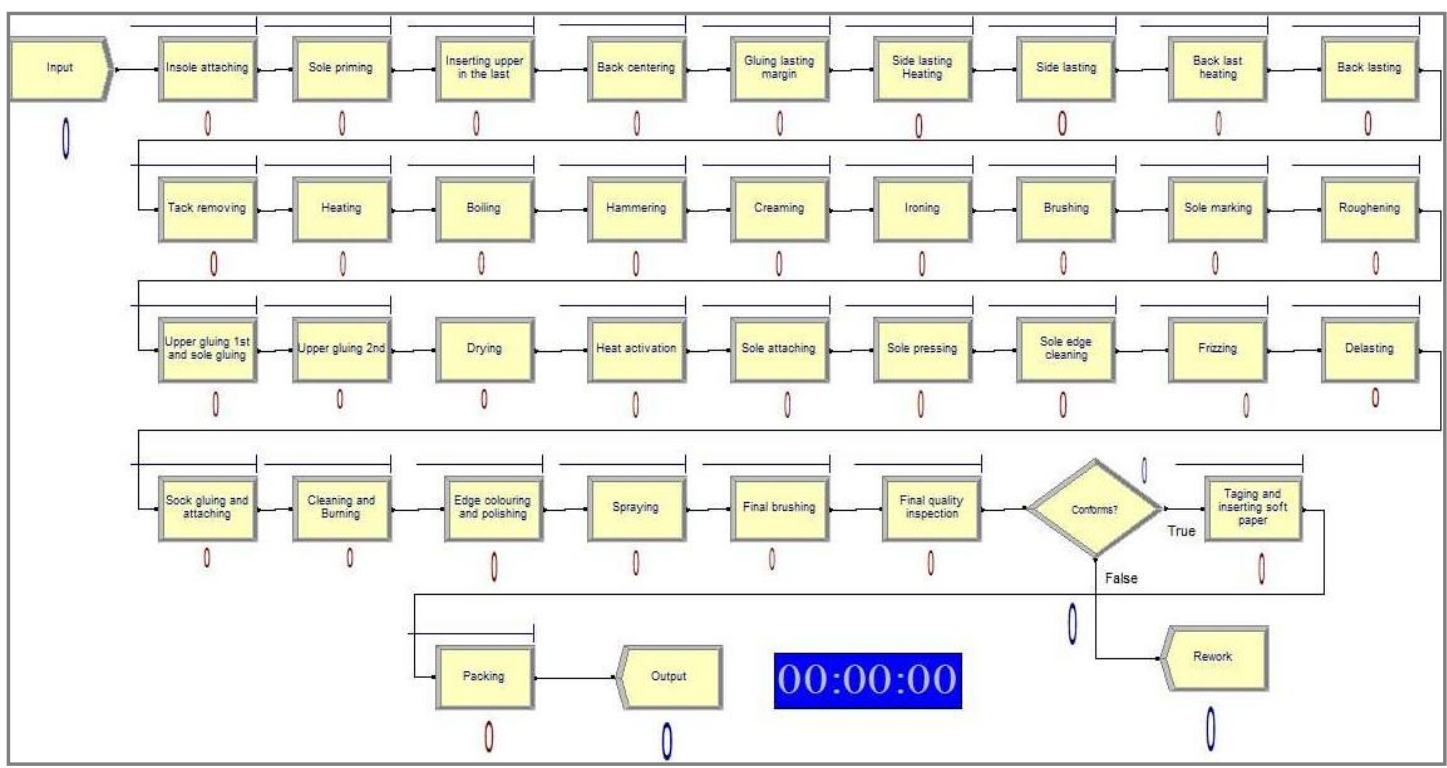

Figure 9: Proposed lasting assembly line simulation model for scenario 1 and 2

Unlike stitching assembly line, all stations in lasting assembly line registered low level of WIP. A maximum of WIP equal to 4 with very minimal average WIP was registered at station stage coloring in simulation running of 41 replications. This shows that the line is loaded below its capacity. So it can be loaded more entities per production cycle time. In other word, we can increase the rate at which entities are loaded on the line. The rate at which entities are loaded or time between loadings of entities for the existing production system is 52 seconds. Reducing this to $45 \mathrm{sec}$ on average, we have the simulation result of: Input increases from 577 to 641, Production output $(P)$ is increased from 531 to 575 , Line efficiency $\mathrm{E} b$ remain the same $67.6 \%$, and Production efficiency $($ Epwc) $=$ Output /Input becomes 575/641 which is equal to $79.9 \%$.

\section{Scenario 4: Changing working method}

In the lasting assembly line, after upper gluing 2 operations they let the glued upper part before attaching it to the external sole to dry conventionally on the conveyor.
This technique requires long conveyor and more time to reach the required state. However, if we install a dryer machine with a capacity of 16 shoes, the length of the conveyor will be shorten by $13.60 \mathrm{~m}$ and the time required for this operation can be decreased from $1138 \mathrm{sec}$ to approximately $420 \mathrm{sec}$.

Therefore changing the work method and running the simulation model we have the following result: Make span or total work content time Twc is decreased from 1227.4 to 1105.61 , line balance efficiency $\mathrm{Eb}$ is decreased from 67.6 to $66.4 \%$, and production efficiency (Ep) is increased to $96 \%$.

Scenario 5: Combination of all the above alternatives with adjustments

Combining all the above four scenarios and running the simulation model, the stitching assembly line efficiency increased to $93.5 \%$ and the lasting assembly line efficiency is increased to $86.3 \%$ which is the highest of the overall scenarios. 
Temesgen Garoma and Nahom Mulugeta

\section{Comparison of Scenarios}

Table 6 below shows the result summary of all proposed scenarios against major performance indicators of the footwear assembly line. From the table of comparisons of both assembly lines, we can see how the different performance measures of the manufacturing
Sci. Technol. Arts Res. J., July-Sep 2014, 3(3): 132-141

process for the proposed scenarios are improved with respect to the existing manufacturing system. Among the proposed scenarios the last scenario, combination of all scenario give us better performance measurement for both assembly lines.

Table 6: Comparison of proposed scenarios against major performance indicators

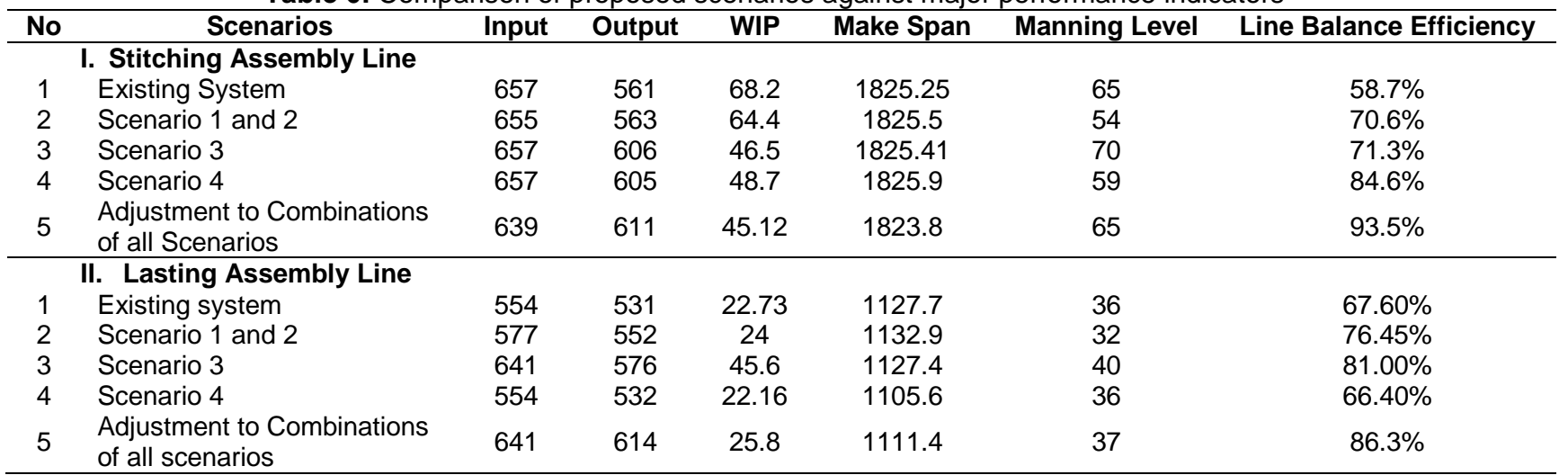

\section{CONCLUSIONS}

Simulation modeling is a powerful and an interactive technique in which we can imitate the real manufacturing system to understand how it behaves if something is altered and evaluates the performance of various strategies and scenarios of manufacturing system. This research is concerned with the modeling and performance analysis of footwear industry. Within the production department, this research is mainly concerned with the modeling and simulation of the two assembly lines: Stitching and Lasting. With student version Arena simulation software, a simple shoe model called moccasin 7101 is selected for the study. This shoe model has 19 parts to be assembled on both assembly lines (stitching and lasting). Collecting and analyzing all the necessary input data using input analyzer of Arena, the simulation model was developed for the existing manufacturing system of this model shoe.

After verifying and validating the developed simulation model, it is simulated for 8 hour working time with 41 replications. After analyzing the result of the simulation run, problems of existing manufacturing system are identified that are: Line balance efficiency for both assembly lines is low, relatively high level of work in process (WIP) is observed in some work station of stitching assembly line, low production output with respect to the installed capacity, and the output of stitching assembly line is significantly higher than that of the lasting assembly line which causes WIP of different model shoes to be piled up in between the two assembly lines.

To solve these identified problems, five possible scenarios were developed like: avoiding unnecessary duplication resource from station with low capacity utilization, merging similar operations with low resource utilization together and assign to one worker, increasing level of resource at stations with high WIP, changing working method, and combination of all the above alternatives. Among the five developed scenarios, the last one, combination of the four alternatives gives better performance of footwear manufacturing for the selected model shoe that increase the manufacturing efficiency of stitching assembly lines from 58.7 to $93.5 \%$ and lasting assembly line from 67.6 to $86.3 \%$.
This computer simulation model can be applied to other similar or different complex manufacturing industries wishing to analyze and improve the performance of the production system. Hence, this research invites other interested researchers to make similar researches to improve the manufacturing processes of industries.

\section{REFERENCES}

Anu Maria (1997). Introduction to Modeling And Simulation. Proceedings of the 1997 Winter Simulation Conference, San Diego, CA, pp. 7-15.

Chance, F., Robinson, J. and Fowler, J. (1996). Supporting manufacturing with simulation: model design, development, and deployment. Proceedings of the 1996 Winter Simulation Conference, San Diego, CA, pp. 1-8.

David A. Takus and David M. Profozich (1997). Arena Software Tutorial; Proccedings of the Winter Simulation Conference, Systems Modeling Corporation; U.S.A.

Desalegn Hailemariam (2009). Mixed Model Assembly Line Balancing Using Simulation Techniques. Addis Ababa University, Sep. 2009.

Groover, P. (2000) Automation, Production Systems, and Computer-Integrated manufacturing, $2^{\text {nd }}$ Edition, Pearson Education, Delhi.

James C. Chen, Chun-Chieh Chen, and Yi-Jhen Lin (2014). Assembly Line Balancing Problem of Sewing Lines in Garment Industry; Proceedings of the 2014 International Conference on Industrial Engineering and Operations Management Bali, Indonesia, January 7-9, 2014.

John, W. Fowler. and Oliver Rose.(2010). Grand Challenges in Modeling and Simulation of Complex Manufacturing Systems. $\quad$ http://www.scs.org/magazines/201001/indexfile/Files/articleCrosbie.pdf.

Law, A.M. and D.W. Kelton. Simulation Modeling and Analysis (3rd Ed.), McGrawHill, New York, 2000.

Law, A.M. and Kelton, D.W. (2000). Simulation Modeling and Analysis (3rd Ed.), McGrawHill, New York, USA.

Peer-Olaf Siebers. (2006); Worker Performance Modeling in Manufacturing Systems Simulation: Proposal for an Agent-Based Approach; University of Nottingham, UK.

Yücesan, E. and Fowler, J. (2000). Simulation Analysis of Manufacturing and Logistics Systems. Encylclopedia of Production and Manufacturing Management, Kluwer Academic Publishers, Boston, Swamidass ed. pp. 687-97. 